\title{
Análises dos principais sais presentes nas águas de poços tubulares em duas comunidades rurais do município de Pombal-PB
}

\section{Analysis the main salts presents in waters of pool tube in two communities countrified the municipality of Pombal -PB}

\author{
Alan Dél Carlos Gomes Chaves ${ }^{1}$; Ricardo Ricelli Pereira de Almeida ${ }^{2}$, Diego Lima Crispim ${ }^{3}$, Augusto César Trigueiro Félix 4 , \\ Patrício Borges Maracajá ${ }^{5}$
}

\begin{abstract}
RESUMO - O uso de água subterrânea captada de poços tubulares para suprir a demanda desse insumo no processo de irrigação para produção de hortaliças nas comunidades de Várzea Comprida dos Oliveiras e Bezerro, vem ocorrendo de forma sistemática pelos agricultores que vivem e trabalham nas suas pequenas propriedades rurais. A água subterrânea é uma reserva estratégica cada vez mais usada devido à escassez hídrica enfrentada pela nossa região nos últimos anos. A pesquisa foi desenvolvida em 2 etapas, sendo a primeira delas o reconhecimento da área de estudo através de visitas in loco nas propriedades dos produtores, na qual foi realizado o levantamento quantitativo dos poços artesianos existentes na comunidade Várzea Comprida dos Oliveiras e na comunidade Bezerro, onde verificou-se um total de 18 (dezoito) poços tubulares, na qual a primeira consta com 11 (onze) poços e a outra com 07 (sete), além da análise da água do rio Piranhas que margeia as duas comunidades. Na segunda etapa foram realizadas as coletas de águas dos poços para análise em laboratório. O trabalho teve como finalidade analisar os principais sais presentes nas águas dos poços tubulares das referidas comunidades. Os parâmetros selecionados para avaliar os níveis da qualidade da água dos poços tubulares foram os seguintes: $\mathrm{K}^{+}, \mathrm{Na}^{+}, \mathrm{Ca}^{+2}, \mathrm{Mg}^{+2}, \mathrm{SO}_{4}{ }^{2-}$, $\mathrm{CO}_{3}{ }^{2-}, \mathrm{HCO}^{3-}, \mathrm{Cl}^{-}, \mathrm{CaCO}_{3}{ }^{-}$. Com base nos dados obtidos dos elementos que foram analisados destacam-se o Cloreto e o Sódio que apresentaram resultados variando entre 0,4 a $2,7 \mathrm{mmol}_{\mathrm{c}} \mathrm{L}^{-1}$ e 0,2 e $3,68 \mathrm{mmol}_{\mathrm{c}} \mathrm{L}^{-1}$ respectivamente, não causando preocupação na utilização da água na irrigação das culturas e nem prejuízo ao sistema de irrigação.
\end{abstract}

Palavras - chave: água subterrânea, reserva estratégica, irrigação, sais e hortaliças.

\begin{abstract}
The use of groundwater extracted from pool to supply the demand of this input in the irrigation process for production of vegetables in Lowland communities of Long Olives and Calf, there has been systematically by farmers who live and work in their small farms. Groundwater is a strategic reserve increasingly used due to water scarcity faced by our region in recent years. The research was conducted in two phases, the first of them the recognition of the study area through site visits in the properties of the producers, which was conducted the quantitative survey of existing wells in the Lowland community of Long Olives and Calf community where there are a total of eighteen (18) wells, in which the first consists in eleven (11) wells and the other with seven (07), and the Piranha river water analysis bordering the two communities. In the second phase were carried out wells of water sampling for laboratory analysis. The work aimed to analyze the main salts present in the water of the wells of these communities. The parameters selected for evaluating the level of the water quality of the wells were as follows: $\mathrm{K}^{+}, \mathrm{Na}^{+}, \mathrm{Ca}^{2+}, \mathrm{Mg}^{2+}, \mathrm{SO}_{4}^{2-}, \mathrm{CaCO}_{3}^{-}, \mathrm{HCO}^{3-}, \mathrm{Cl}^{-}, \mathrm{CaCO}_{3}$. Based on the data elements that were analyzed include the sodium and chloride results showed that varying ranged from 0.4 to $2.7 \mathrm{~L}^{-1}$ and $0.2 \mathrm{mmol}$ and $3.68 \mathrm{mmol}$, respectively $\mathrm{L}^{-1}$, not causing concern the use of water for irrigation of crops and even damage to the irrigation system.
\end{abstract}

Key words: underground water, strategic reserve, irrigation, salts and greenery.

\footnotetext{
*Autor para correspondência

Recebido para publicação em 23/03/2015; aprovado em: 02/07/2015

${ }^{1}$ Mestre em Sistemas Agroindustriais; CCTA/UFCG, Telefone: (83) 96589908; Campus de Pombal-PB, E-mail: alandcgc@ hotmail.com

${ }^{2}$ Graduado em Engenharia Ambiental; CCTA/UFCG, Campus de Pombal-PB, E-mail: ricelli2008@bol.com.br

${ }^{3}$ Engenheiro Ambiental, UFCG. Especializando em Educação Ambiental e Geografia do Semiárido, IFRN. Mestrando do Programa de Pós -Graduação em Sistemas Agroindustriais (PPGSA), UFCG. E-mail: diegolc_85@hotmail.com

${ }^{4}$ Graduado em Engenharia Civil, pela Universidade Federal de Campina Grande, Campus de Campina Grande-PB/CTRN; E-mail: augusto_cesar3@hotmail.com

${ }^{5}$ Engenheiro Agrônomo, Doutor em Agronomia - Professor da Universidade Federal de Campina Grande (UFCG/CCTA/UAGRA) E-mail:

patrício@ufcg.edu.br
} 


\section{INTRODUÇÃO}

Segundo Farias (2006), durante séculos, a humanidade considerou a água como um recurso inesgotável, e a utilizou de forma predatória e insustentável.

Os recursos hídricos estão enfrentando uma grande pressão do crescimento rápido da demanda por água, sendo as principais atividades: a agricultura, a produção de energia, os usos industriais e o consumo humano, destacando-se o setor agrícola como o maior usuário na maioria dos países em desenvolvimento. A irrigação é responsável pelo consumo da maior parte do recurso mineral, entre 70 e $80 \%$ no mundo enquanto que no Brasil estudos recentes mostram que a utilização de água na agricultura representa aproximadamente $70 \%$ do consumo total de água doce no país (GRAMOLELLI JÚNIOR, 2004).

Diante desse panorama, verifica-se uma incessante preocupação, no tocante ao uso racional dos recursos hídricos na irrigação, objetivando-se o controle do desperdício e buscando alternativas que possa otimizar a demanda. Bem como, a necessidade de realizar ações de monitoramento da qualidade e a quantidade de água que são utilizadas na irrigação das culturas agrícolas.

No que diz respeito ao monitoramento de parâmetros de qualidade da água constitui-se em uma ferramenta básica para avaliar alterações ambientais causadas pela ação antrópica (MOLOZZI et al., 2006). Assim, é de fundamental importância para o cultivo de alimentos mais saudável, como também para um melhor funcionamento dos equipamentos de irrigação. Porém, na agricultura irrigada o aspecto da qualidade da água tem sido menosprezado em razão de que, no passado, em geral as fontes hídricas, eram abundantes, de boa qualidade e de fácil utilização, este cenário está sendo modificado em diversos lugares (SILVA et al., 2011).

Para Mantovani et al., (2006) a qualidade da água é um aspecto essencial para um melhor aproveitamento nos sistemas de irrigação, ainda assim, a análise da qualidade da água é , constantemente, tratada com descaso no momento na preparação dos projetos. Como resultado disso, a irrigação poderá possivelmente causar efeitos indesejáveis nas culturas agrícolas, servindo de canal de propagação para contaminação da população, no instante em que ocorrer o consumo de alimentos que receberam a água contaminada.

$\mathrm{O}$ processo de salinização dos solos e das águas subterrâneas e superficiais é um dos mais importantes problemas de degradação ambiental, com seus efeitos prejudiciais sendo mais pronunciados nas áreas de regiões áridas e semiáridas, e que vem crescendo rapidamente em diversas partes do globo, causando problemas de grandes proporções na produtividade das culturas agrícolas. Numa escala mundial, existe uma área de aproximadamente 400 milhões de hectares de terras utilizada com agricultura, porém cuja produção vem sendo severamente restringida pela salinidade (Bot et al., 2000).

Por sua vez, a água de irrigação, independente de sua origem, é o principal meio de aporte de sais ao solo (salinização secundária ou antrópica). Como todas as águas naturais, sejam elas de origem meteórica (chuva), superficial (rios, lagos, açudes, etc.) ou subterrânea (aquíferos) - contêm quantidades variáveis de sais solúveis, a aplicação de água ao solo pela irrigação implica, necessariamente, adição de sais ao seu perfil. Os sais, que são transportados pelas águas de irrigação e depositados no solo, acumulam-se neste após se concentrarem, à medida que a água se evapora ou é consumida pelas plantas. E, se estes sais - que vão progressivamente se acumulando na zona radicular - não forem eliminados por meio de lixiviação (lavagem dos sais do solo) e drenagem, a salinização do solo será inevitável e poderá atingir níveis que tornem a sua exploração economicamente inviável.

A salinização do solo pode provocar, ainda, um efeito indireto bastante adverso ao crescimento das plantas: a destruição da estrutura do solo e consequente compactação deste. Tal ocorre devido à dispersão das partículas de argila causada pela substituição dos íons cálcio $\left(\mathrm{Ca}^{2+}\right)$ e magnésio $\left(\mathrm{Mg}^{2+}\right)$ presentes no complexo de troca pelo sódio $\left(\mathrm{Na}^{+}\right)$, resultando, assim, na elevação da sodicidade do solo. Ou seja, na porcentagem de sódio trocável (PST), que, em última instância, é o principal fator responsável pela deterioração das propriedades físicas dos solos afetados por sais (sódicos, ou alcalinos, e salino-sódicos). Além dos efeitos negativos decorrentes da facilidade ao encharcamento e da má aeração, comuns em solos compactados, a alta PST torna a atividade agrícola quase impraticável e antieconômica em solos sódicos, por ser o seu manejo bastante difícil e a sua recuperação muito dispendiosa.

O trabalho teve como finalidade analisar os principais sais presentes nas águas dos poços tubulares das referidas comunidades.

\section{MATERIAL E MÉTODOS}

O estudo foi desenvolvido nas comunidades Várzea Comprida dos Oliveiras e Bezerro, localizadas na zona rural do município de Pombal - PB. Essas duas comunidades destacam-se no município pelo cultivo de hortaliças, atividade essa que apresenta uma rentabilidade econômica para os agricultores dessas localidades.

O município de Pombal - PB é um dos mais antigos do estado da Paraíba, é o segundo maior do estado da Paraíba em extensão territorial possuindo $889 \mathrm{~km}^{2}$. Segundo o IBGE (Instituto Brasileiro de Geografia e Estatística), a população em 2010 era estimada em 32.110 habitantes.

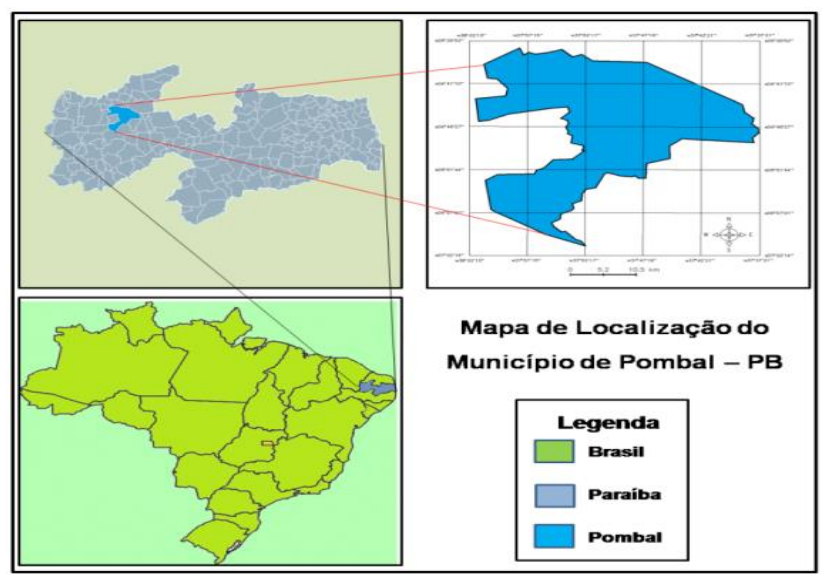

Figura 1: Localização do Município de Pombal-PB Fonte: Sousa, 2015

A pesquisa foi desenvolvida em 2 etapas, sendo a primeira delas o reconhecimento da área de estudo através de visitas in loco nas propriedades dos produtores, na qual foi realizado o levantamento quantitativo dos poços artesianos 
existentes na comunidade Várzea Comprida dos Oliveiras e da comunidade Bezerro, onde verificou-se um total de 18 (dezoito) poços tubulares, na qual a primeira consta com 11 (onze) poços e a outra com 07 (sete).

Na segunda etapa foram realizadas as coletas de água nos 18 poços das duas comunidades sempre no período da manhã.

As coletas de amostras de água foram realizadas entre o período de 11/2013 - 05/2014, levando em consideração o período de menor e maior precipitação pluviométrica na área de estudo.

Os parâmetros selecionados para avaliar os níveis de qualidade da água foram: $\mathrm{K}^{+}, \mathrm{Na}^{+}, \mathrm{Ca}^{+2}, \mathrm{Mg}^{+2}, \mathrm{SO}_{4}{ }^{2-}, \mathrm{CO}_{3}{ }^{2-}$ ${ }^{\prime} \mathrm{HCO}^{3-}, \mathrm{Cl}^{-}, \mathrm{CaCO}_{3}$.
Poço 1

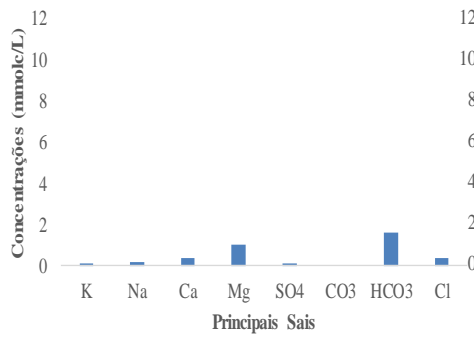

Poç0 4

Poço 5
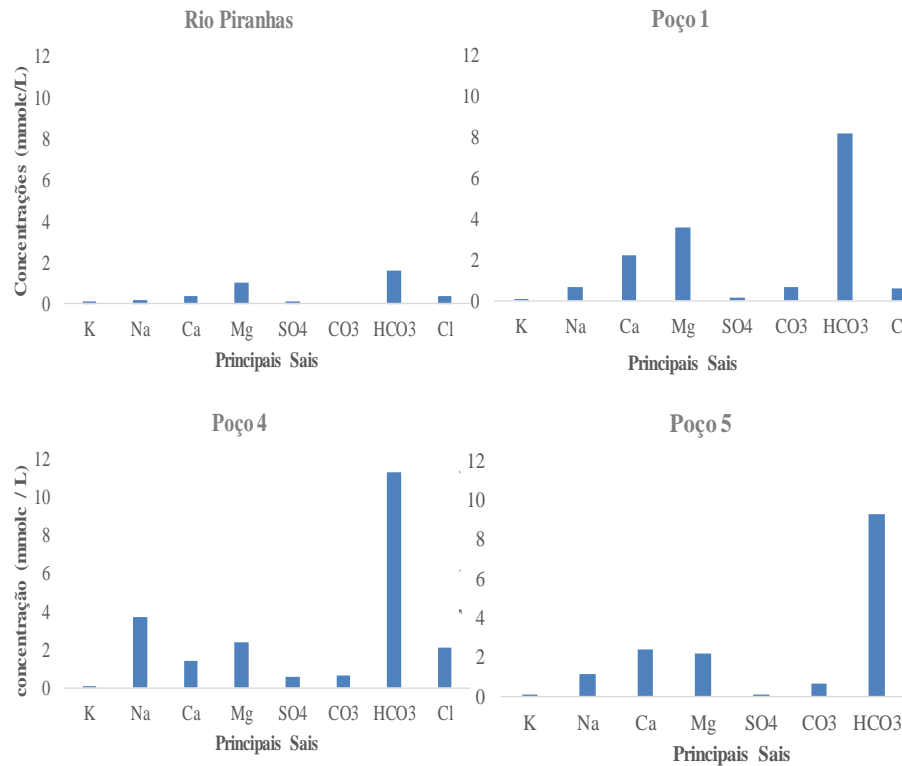

Poço 8
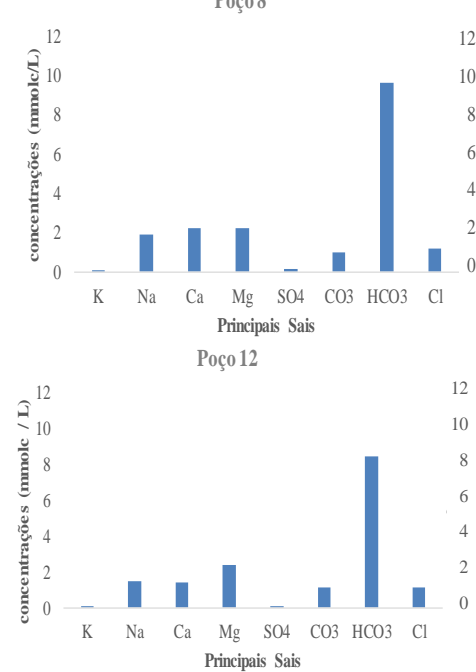

Poço 16
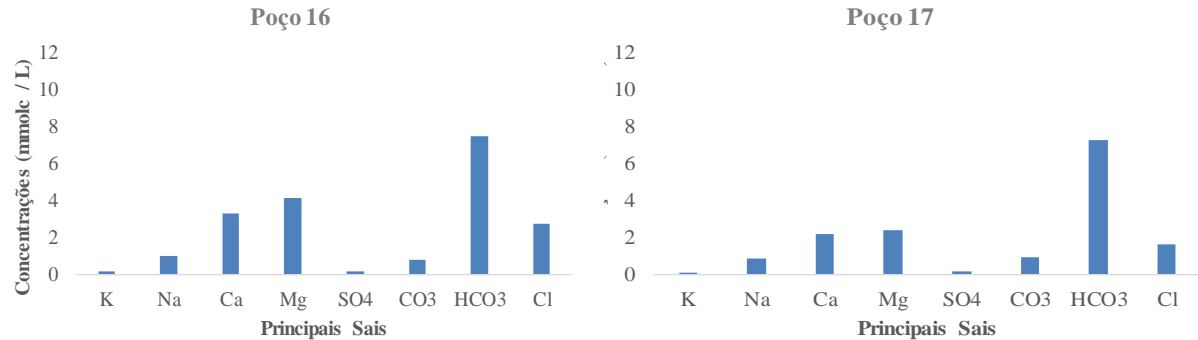

Poço3

Poco6 Poço 7

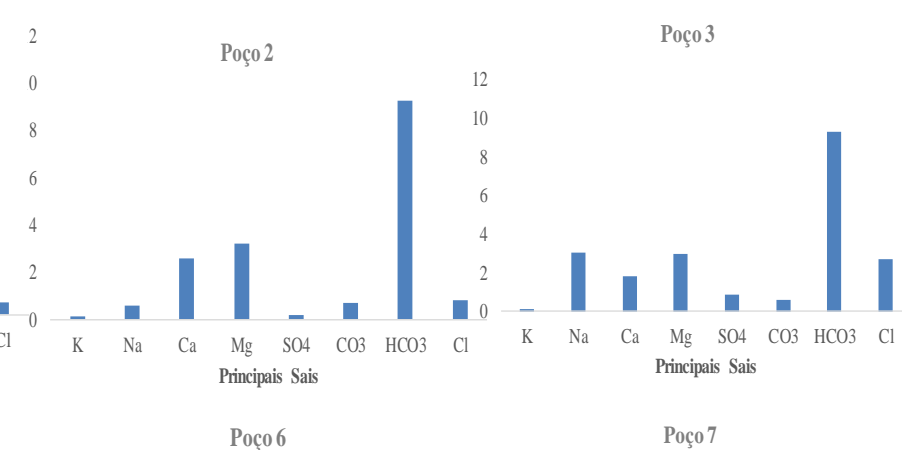
de acordo com os métodos do Manual da FUNASA 2004. Algumas análises foram realizadas in loco, enquanto outras foram encaminhadas para serem realizadas no laboratório de análises de solo e água - (IFPB/ Sousa).

\section{RESULTADOS E DISCUSSÃO}

$\mathrm{Na}$ figura 2 estão representadas as principais concentrações dos sais encontrados na análise das águas dos poços das comunidades Bezerro e Várzea Comprida dos Oliveira.

Figura 2: Concentrações dos principais sais encontrados nos poços das comunidades Bezerro e Várzea Comprida dos Oliveira 
Conforme os resultados obtidos, observou-se que o Bicarbonato $\left(\mathrm{HCO}_{3}{ }^{-}\right)$foi o ânion que apresentou os maiores resultados em todos os poços, com valores variando de 11,32 $\mathrm{mmol}_{\mathrm{c}} / \mathrm{L}$ no poço 4 a $1,58 \mathrm{mmol}_{\mathrm{c}} \mathrm{L}^{-1}$. Os poços 18,10 e 6 apresentaram concentrações de $11,10,42$ e 10,34 mmol $_{\mathrm{c}} / \mathrm{L}$ de $\mathrm{HCO}_{3}$. Medeiros el at (2003) encontrou valores de $\mathrm{HCO}_{3}$ acima de $5 \mathrm{mmol}_{\mathrm{c}} \mathrm{L}^{-1}$ estudando as concentrações de sais em poços da região de Mossoró-Baraúna.

Resultados acima de 5 mmol $_{c} \mathrm{~L}^{-1}$ na água de irrigação podem provocar precipitação de fertilizantes fosfatados, quando adicionados, causando obstrução dos emissores. Nas águas que contêm concentrações elevadas de íons de $\mathrm{HCO}_{3}{ }^{-}$, há tendência de ocorrer precipitação de cálcio e magnésio, sob forma de carbonatos, reduzindo, assim, as concentrações desses íons, aumentando o a proporção de sódio (BERNARDO, SOARES, MANTOVANNI, 2011). Resultados semelhantes foram encontrados por Alencar (2007) avaliando a qualidade das águas dos poços do calcário jandaira, verificou valor médio de 4,0 $\mathrm{mmol}_{\mathrm{c}}$ / L.

Silva et al. (2003) avaliando a qualidade química das águas de poços da região sudeste do estado do Piauí, encontraram valores de 134, 170 e $313 \mathrm{mg} / \mathrm{L}_{\text {de }}$ de $\mathrm{HCO}_{3}$ para poços dos municípios de Padre Marcos, Picos e Pio IX respectivamente. Lima et al., (2007) avaliando o efeito da salinidade na cultura da mamona, obtiveram seis

níveis de salinidade na água de irrigação $(0,5,1,0,1,5,2,0$ e $\left.2,5 \mathrm{dS} \mathrm{m}^{-1}\right)$, e concentrações de $\mathrm{HCO}_{3}{ }^{-}(2,3,4,0,3,3,3,5,3,3$, $\left.3,7 \mathrm{mmol}_{\mathrm{c}} \mathrm{L}^{-1}\right)$, observando assim uma relação entre as duas variáveis, um pequeno aumento do teor de $\mathrm{HCO}_{3}^{-}$com aumento da salinidade.

$\mathrm{O}$ carbonato $\left(\mathrm{CO}_{3}{ }^{2-}\right)$ apresentou os maiores valores nos poços 11,18 e 10 , com 1,34, 1,14 e 1,12 mmol $_{c} \mathrm{~L}^{-1}$. Os poções 2, 5 e 17 apresentaram resultados de 0,72, 0,64 e 0,94 $\mathrm{mmol}_{\mathrm{c}} \mathrm{L}^{-1}$. Rocha (2008) avaliando a concentração de $\mathrm{CO}_{3}{ }^{2-}$ nas aguas de poços na bacia do Rio dos peixes, verificaram $0,0 \mathrm{mmol}_{\mathrm{c}} \mathrm{L}^{-1}$. No entanto, o valor de $\mathrm{pH}$ medido no campo foi igual a 8,41 na localidade de Canabrava, indicando a presença de carbonatos, o que não ocorreu na análise laboratorial. A sua ausência pode ser explicada devido à reação entre o dióxido de carbono presente no ar atmosférico com os carbonatos para formar bicarbonatos. Entre os íons estudados neste trabalho, o potássio e o sulfato foram o que apresentaram os menores resultados entre os poços. Foi verificado que os valores de potássio variaram de 0,02 a 0,12 $\mathrm{mmol}_{\mathrm{c}} / \mathrm{L}$ nos poços 12 e 16 . O potássio apresentou os menores valores entre os ions analisados, com valor médio de 0,07 $\mathrm{mmol}_{\mathrm{c}} / \mathrm{L}$.

Alencar (2007) monitorando a qualidade das águas de poços da região Mossoró-Baraúna, observou resultados $0,06 \mathrm{mmol}_{\mathrm{c}} / \mathrm{L}$ de potássio em poços do município de Baraúna e 0,41 $\mathrm{mmol}_{\mathrm{c}} / \mathrm{L}$ nos poços da comunidade Gangorra, pertencente ao município de Mossoró. Costa e Gheyi (1984) observaram valores de potássio 0,03 a 0,31 em poços do município de São Bento-PB e Brejo do Cruz-PB. Lima et al., (2007) observou uma relação entre CE (condutividade elétrica) da água com o teor de potássio, com a obtenção de cinco níveis de agua salina $(0,5,1,0,1,5,2,0$, $2,5 \mathrm{dS} \mathrm{m}^{-1}$ ) no trabalho, os valores de potássio aumentaram linearmente $\left(0,24,0,34,0,40,0,46,0,51\right.$ e $\left.0,58 \mathrm{mmol}_{\mathrm{c}} / \mathrm{L}\right)$.

$\mathrm{O}$ sulfato apresentou resultados que variaram de 0,05 $\mathrm{mmol}_{\mathrm{c}} / \mathrm{L}$ no poço e uma concentração de $0,86 \mathrm{mmol}_{\mathrm{c}} / \mathrm{L}$ no poço 3. Notou-se o sulfato apresentou um valor médio de 0,21 $\mathrm{mmol}_{\mathrm{c}} / \mathrm{L}$. A presença de um íon em excesso poderá provocar deficiência ou inibir a absorção de outro, devido à precipitação. $\mathrm{O}$ excesso de sulfato pode ocasionar a precipitação do cálcio, afetando o crescimento da planta pela falta do elemento precipitado e não pelo excesso de outro íon. Segundo Pizarro (1978), as culturas bananeira e o Alface são afetadas pelo alto teor de sulfato na água de irrigação. Em uma pesquisa realizada por Costa e Gheyi (1984) avaliando a qualidade das águas nos poços da microrregião do município de Catolé do Rocha-PB, observaram valores de sulfatos 0,5 $\mathrm{mmol}_{\mathrm{c}} / \mathrm{L}$ em poços de Jerico-PB e 1,00 $\mathrm{mmol}_{\mathrm{c}} / \mathrm{L}$ em Bom sucesso.

De acordo com o apresentado, os íons o cálcio $\left(\mathrm{Ca}^{2+}\right)$ e o magnésio $\left(\mathrm{Mg}^{2+}\right)$ foram em média o segundo e o terceiro mais concentrado nas águas avaliadas neste trabalho. $\mathrm{O}$ cálcio apresentou valores de 3,3 $\mathrm{mmol}_{\mathrm{c}} / \mathrm{L}$ no poço $16,2,4 \mathrm{mmol}_{\mathrm{c}}$ / $\mathrm{L}$ nos poços 5 e 6, 1,4 $\mathrm{mmol}_{\mathrm{c}} / \mathrm{L}$ no poço 10 (Figura 32J) e $0,9 \mathrm{mmol}_{\mathrm{c}} / \mathrm{L}$ no poço 11 , com valor médio $1,9 \mathrm{mmol}_{\mathrm{c}} / \mathrm{L}$. O íon $\mathrm{Mg}^{2+}$ também apresentou o maior e o menor resultado nos poços 16 e 11, como foi visto para o $\mathrm{Ca}^{2+}$, mostrando assim, uma relação entre esses dois elementos na água. Os teores de $\mathrm{Ca}^{2+}$ e $\mathrm{Mg}^{2+}$ na água de irrigação são afetados pela concentração de bicarbonato na água, pois um aumento no teor de bicarbonato na água de irrigação ocasionara formação de precipitados, no caso, o carbonato de cálcio e de magnésio $\left(\mathrm{CaCO}_{3}\right.$ e $\left.\mathrm{MgCO}_{3}\right)$.

Medeiros et al., (2003) verificou que em todos os poços analisados a concentração de cálcio estava bastante alto, sendo que as águas das comunidades de Boa Água, Cacimba Funda, Mata Fresca e Serra Mossoró as que apresentaram maiores valores para esses íons. Medeiros et al., (2003) também mostrou uma tabela com uma relação entre a

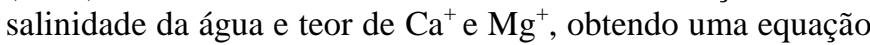
$\mathrm{Y}=4,75 \mathrm{X}+4,56$, Martins (1993) e Silva Júnior et al. (1999) encontraram resultados semelhantes com outras águas do Nordeste do Brasil. Oliveira e Maia obtiveram resultados similares a esse trabalho, estudando a concentração de sais em poços na chapada do Apodi, encontrou valor médio de 3,33 $\mathrm{mmol}_{\mathrm{c}} / \mathrm{L}$ de cálcio e 2,9 $\mathrm{mmol}_{\mathrm{c}} / \mathrm{L}$ de magnésio.

Junior, Gheyi e Medeiros (1999) observaram valores de $\mathrm{Ca}^{2+}\left(1,47,4,2\right.$, e 2,75 $\left.\mathrm{mmol}_{\mathrm{c}} / \mathrm{L}\right)$ em poços dos municípios de Pau dos Ferros-RN, Boqueirão-PB e Picuí-PB,

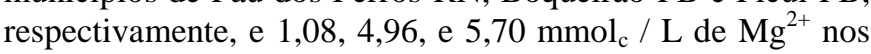
respectivos municípios. Alencar (2007) observou valores de Cálcio que variaram entre 6,2 e $26,5 \mathrm{mmol}_{\mathrm{c}} \cdot \mathrm{L}^{-1}$ na $1^{\mathrm{a}}$ coleta e 7,1 e 23,7 mmolc. $\mathrm{L}^{-1}$ na $4^{\text {a }}$ coleta, onde apenas a localidade de Gangorra apresentou valores considerados acima dos normais (>20 mmolc. $\mathrm{L}^{-1}$ ). Com relação ao $\mathrm{Mg}^{2+}$, os valores variaram entre 2,69 e 8,53 mmolc. $\mathrm{L}^{-1}$ na $1^{\text {a }}$ leitura e entre 2,6 e 15,4 mmolc. $\mathrm{L}^{-1}$ na $4^{\mathrm{a}}$, com a localidade de Gangorra apresentando os maiores valores nas 48 duas épocas. Estes valores são considerados por Ayers \& Westcot, (1999) acima do normal (0- 5 mmol $\left._{\mathrm{c}} \cdot \mathrm{L}^{-1}\right)$.

$\mathrm{O}$ cloreto $\left(\mathrm{Cl}^{-}\right)$e o sódio $\left(\mathrm{Na}^{+}\right)$na água dos poços apresentaram valores médios de $1,5 \mathrm{mmol}_{\mathrm{c}} \mathrm{L}^{-1}$. No poço 13 foi observado o maior valor de $\mathrm{Cl}^{-}\left(2,5 \mathrm{mmol}_{\mathrm{c}} \mathrm{L}^{-1}\right)$, já no poço $2 \mathrm{~A}$ foi verificado o menor valor de $\mathrm{Cl}^{-}\left(0,6 \mathrm{mmol}_{\mathrm{c}} \mathrm{L}^{-1}\right)$. Resultados semelhantes foram encontrados por Junior, Gheyi e Medeiros (1999), Medeiros et al., (2003), onde encontraram valores de $\mathrm{Cl}^{-}$variando entre 4,4 e $6,9 \mathrm{mmol}_{\mathrm{c}} \mathrm{L}^{-1}$. 
$\mathrm{O} \mathrm{Cl}^{-}$é um íon que se tornara toxico para planta quando a mesma absorve em excesso, $\mathrm{O}$ cloreto não é retido nem adsorvido pelas partículas do solo, deslocando-se facilmente com a água do solo, mas é absorvido pelas raízes e translocado às folhas, onde se acumula pela transpiração. A sensibilidade das culturas a este íon é bastante variável como, por exemplo, as frutíferas, que começa a mostrar sintomas de danos a concentrações acima de $0,3 \%$ de cloreto, em base de peso seco, as espécies tolerantes podem acumular até 4,0 a $5,0 \%$ de cloreto sem manifestar qualquer sintoma de toxicidade (DIAS \& BLANCO, 2010).

Alencar (2007) estudando as concentrações de sais nas águas de irrigação observou que em quase todos os poços da região Mossoró-Baraúna apresentou resultados no teor de cloreto acima de $10 \mathrm{mmol}_{\mathrm{c}} \mathrm{L}^{-1}$, o mesmo também observou uma relação entre $\mathrm{CE} \times \mathrm{Cl}^{-}$, pois com o aumento linear da concentração de $\mathrm{Cl}^{-}$houve também uma ascensão linear na curva de Condutividade elétrica. Maia, Morais e Oliveira (1998) também observaram uma forte relação entre $\mathrm{CE} \mathrm{x} \mathrm{Cl}^{-}$, com $\mathrm{R}^{2}$ igual a 0,85 .

O sódio obteve os maiores resultados nos poços 3,4 e 15 , com valores de 3,68, 3,08 e 2,97 mmol $_{\mathrm{c}} \mathrm{L}^{-1}$, e o menor foi encontrado estudando o poço 14. Resultados similares foram notado por Medeiros et al., (2003), onde os valores variaram de 2,9 a $4,9 \mathrm{mmol}_{\mathrm{c}} \mathrm{L}^{-1}$.

A toxicidade ao sódio é mais difícil de diagnosticar que ao cloreto, porém tem sido identificada claramente como resultado de alta proporção de sódio na água. Ao contrário dos sintomas de toxicidade do cloreto, que têm início no ápice das folhas, os sintomas típicos do sódio aparecem em forma de queimaduras ou necrose, ao longo das bordas (DIAS \& BLANCO, 2010).

O excesso de sódio no solo, mais precisamente, com PST (percentagem de sódio trocável) acima de $15 \%$, pode acarreta em um problema desastroso no solo, chamado de sodicidade. $\mathrm{O}$ sódio além de causar toxidez na planta, pode ocasionar a desestruturação do solo. De modo generalizado, os solos sódicos, ou seja, com excesso de sódio trocável, apresentam problemas de permeabilidade e qualquer excesso de água causará encharcamento na superfície do solo, impedindo a germinação das sementes e o crescimento das plantas, por falta de aeração.

Resultados obtidos por Alencar (2007) demonstraram uma baixa concentração de sódio, sendo inferior a cálcio, mostrando que não há muito problema por parte do mesmo. Lima et al., (2007) verificou que há uma relação entre $\mathrm{CE} \times \mathrm{Na}^{+}$, com valores de $\mathrm{CE}(0,5,1,0,1,5,2,0$, $\left.2,5 \mathrm{dS} \mathrm{m}^{-1}\right)$ e $\mathrm{Na}^{+}(3,67,7,49,10,96,13,96,16,82$ e 29,77 $\mathrm{mmol}_{\mathrm{c}} \mathrm{L}^{-1}$ ). Maia, Morais e Oliveira (1998) obtiveram um coeficiente de relação $\mathrm{R}^{2}$ igual 0,87 , mostrando uma forte relação entre essas variáveis.

\section{CONCLUSÃO}

Verificou-se que a água dos poços tubulares retiradas para irrigação de hortaliças nas comunidades Várzea Comprida dos Oliveiras e Bezerro, apresentaram as maiores concentrações do ânion Bicarbonato $\left(\mathrm{HCO}_{3}{ }^{-}\right)$. Resultados acima de $5 \mathrm{mmol}_{\mathrm{c}} \mathrm{L}^{-1}$ na água de irrigação podem provocar precipitação de fertilizantes fosfatados, quando adicionados, causando obstrução dos emissores.
$\mathrm{O}$ carbonato $\left(\mathrm{CO}_{3}{ }^{2-}\right)$ apresentou os maiores valores nos poços 11,18 e 10 , com 1,34, 1,14 e 1,12 mmol $_{c} \mathrm{~L}^{-1}$. Os poções 2,5 e 17 apresentaram resultados de 0,72, 0,64 e 0,94 mmol $_{\mathrm{c}} \mathrm{L}^{-1}$. O cloreto $\left(\mathrm{Cl}^{-}\right)$e o sódio $\left(\mathrm{Na}^{+}\right)$na água dos poços apresentaram valores médios de $1,5 \mathrm{mmol}_{\mathrm{c}} \mathrm{L}^{-1}$.

$\mathrm{O} \mathrm{Cl}^{-}$é um íon que se tornara tóxico para planta quando a mesma absorve em excesso, $\mathrm{O}$ cloreto não é retido nem adsorvido pelas partículas do solo, deslocando - se facilmente com a água do solo, mas é absorvido pelas raízes e translocado às folhas, onde se acumula pela transpiração.

O sulfato apresentou resultados que variaram de 0,05 $\mathrm{mmol}_{\mathrm{c}} / \mathrm{L}$ no poço 5 e uma concentração de $0,86 \mathrm{mmol}_{\mathrm{c}} / \mathrm{L}$ no poço 3. Notou-se o sulfato apresentou um valor médio de 0,21 $\mathrm{mmol}_{\mathrm{c}} / \mathrm{L}$. A presença de um íon em excesso poderá provocar deficiência ou inibir a absorção de outro, devido à precipitação.

O excesso de sulfato pode ocasionar a precipitação do cálcio, afetando o crescimento da planta pela falta do elemento precipitado e não pelo excesso de outro íon.

De acordo com o apresentado, os íons o cálcio $\left(\mathrm{Ca}^{2+}\right)$ e o magnésio $\left(\mathrm{Mg}^{2+}\right)$ foram em média o segundo e o terceiro mais concentrado nas águas avaliadas neste trabalho. $\mathrm{O}$ cálcio apresentou valores de $3,3 \mathrm{mmol}_{\mathrm{c}} / \mathrm{L}$ no poço 16 e uma concentração 2,4 $\mathrm{mmol}_{\mathrm{c}} / \mathrm{L}$ nos poços 5 e 6, 1,4 $\mathrm{mmol}_{\mathrm{c}} / \mathrm{L}$ no poço 10 e $0,9 \mathrm{mmol}_{\mathrm{c}} / \mathrm{L}$ no poço 11 , com valor médio 1,9 $\mathrm{mmol}_{\mathrm{c}} / \mathrm{L}$.

O sódio obteve os maiores resultados nos poços 3,4 e 15 , com valores de $3,68,3,08$ e $2,97 \mathrm{mmol}_{\mathrm{c}} \mathrm{L}^{-1}$, e o menor foi encontrado estudando o poço 14 .

A toxicidade ao sódio é mais difícil de diagnosticar que ao cloreto, porém tem sido identificada claramente como resultado de alta proporção de sódio na água.

\section{REFERÊNCIAS BIBLIOGRÁFICAS}

ALLEN, R. G.; PEREIRA, L. S.; RAES, D.; SMITH, J. Evapotranspiration del cultivo:guias para la determinación de los requerimientos de agua de los cultivos. Roma: FAO, 2006. 298p. (FAO, Estudio Riego e Drenaje Paper, 56).

ANDRIOLO, J.L. Fisiologia das culturas protegidas. Santa Maria: UFSM, 1999. 142p.

ARAÚJO, W. F.; BOTREL, T. A.; CARMELLO, Q. A. C.; SAMPAIO, R. A.; VASCONCELOS, M. R. B. marcha de absorção de nutrientes pela cultura da abobrinha conduzida sob fertirrigação. In: FOLEGATTI, M. V.; CASARINI, E.; BLANCO, F. F.; BRASIL, R. P. C.; RESENDE, R. S. Fertirrigação: flores, frutas e hortaliças. Guaíba: Agropecuária, 2001, v. 1, p. 67-77. BENINCAS, M. M. P. Análise de crescimento de plantas. Jaboticabal, SP: FCAV- UNESP, 1988. 41p. 
AYERS, R. S.; WESTCOT, D. W. A qualidade da água na agricultura. Campina Grande: UFPB, 1991. 218 p. (Tradução).

BIELESKI, R.L Phosphate pools, phosphate transport, and phosphate availability. Ann. Rev. Plant Physiol, 24: $225-$ 252,1973 .

BRAGA, J. M.; DEFELIPO B. V. Determinação espectrofotométrica de fósforo em extratos de solos e plantas. Revista Ceres, Viçosa, MG, v. 21, n. 1, p. 73-85, 1974.

CARDOSO, M. J.; FONTES, L. A. N.; LOPES, N. F. Partição de assimilados e produção de matéria seca de milho em dois sistemas de associação com feijão (Phaseolus vulgares L.). Revista Ceres, Viçosa, v. 34, n. 191, p. 71 89, 1987.

CARMO FILHO, F.; OLIVEIRA, O. F. Mossoró: um município do semiárido nordestino, caracterização climática e aspecto florístico. Mossoró: ESAM, 1995. 62p. (Coleção Mossoroense, série B).

DUARTE, S. R. Alterações na nutrição mineral do meloeiro em função da salinidade da água de irrigação. Campina Grande: 2002. 70p. Dissertação Mestrado.

FURLANI, A. M. C. Nutrição mineral. In: KERBAUY, G. B. Fisiologia vegetal. Rio de Janeiro, Guanabara koogan, 2004. p. 40-75.

GRANGEIRO, L. C.;CECÍlIO FILHO, A. B. Acúmulo e exportação de macronutrientes pelo híbrido de melancia Tide. Horticultura Brasileira, Brasília, v. 22, n. 1, p. 9397, 2004

GRANGEIRO L. C.; CECÍllo FILHO A. B. Acúmulo e exportação de macronutrientes em melancia sem sementes. Horticultura Brasileira, Brasília, v. 23, p. 763 767,2005 .

GRANGEIRO, L. C.; CECÍLIO FILHO, A. B.; CAZETTA, J. O. Concentrações de nutrientes no limbo foliar de melancia em função de épocas de cultivo, fontes e doses de potássio. Horticultura Brasileira, Brasília, v.22, n.4, p. 740-743, out-dez 2004

HALSTED, M.; LYNCH, J. Phosphorus responses of C3 and c4 species. Journal of Experimental Botany, Lancaster, v. 47 , p. $497-505,1996$

ISRAEL, D. W.; RUFTY JR., T. W. Influence phosphorus nutrition on phosphorus and nitrogen utilization and associated physiological responses in soybean. Crop Science, Madison, v. 28, p. 954-960. 1988.

LARCHER, W. Physiological plant ecology. Berlin: Springer, 1995. 448p.

LAMIKANRA, O.; WATSON, M.A. Effect of calcium treatment temperature on fresh-cut cantaloupe melon during storage. Journal of Food Science, v.69, n. 6, 2004.

LIMA, A. A. de. Absorção e eficiência de utilização de nutrientes por híbridos de melão (Cucumis melo L.). 60f. Dissertação (Mestrado em Solos e Nutrição de plantas), Universidade Federaldo Ceará, Fortaleza, 2001.
LINDHAUER, M.G. The role of potassium in the plant with emphasis on stress conditions (water, temperature, salinity). In: PROCEEDINGS OF THE POTASSIUM SYMPOSIUM. Pretoria, 1985. Proceedings. Pretoria, Internacional Potash Institute and Fertilizer Society of South Agrica, 1985. P. 95-113.

LINHARES, L.A.; SANTOS, C.D.; ABREU, C.M.P; CORRÊA, A.D. Transformações químicas, físicas $\mathrm{e}$ enzimáticas de goiabas "Pedro Sato" tratadas na póscolheita com cloreto de cálcio e 1-metilciclopropeno e armazenadas sob refrigeração. Ciência e Agrotecnologia, v.31, n.3, 2007.

LOPES, A. S. Manual Internacional de Fertilidade do Solo. 2 ed. rev. e amp. Piracicaba: POTAFOS, 1998. 177p.

PRATA, E. B. Acumulação de biomassa e absorção de nutrientes por híbridos de meloeiro (Cucumis melo L.) 1999. 37f. Dissertação (Mestrado em Solos e Nutrição de Plantas, universidade Federal do Ceará, Fortaleza), 1999.

ROLLE, R.; CHISM, G.W.Physiological consequences of minimally processed fruits and vegetables.Journal of Food Quality, Oxford, v.10, 1987.

SILVA, F. C. (Ed. Técnico). Manual de Análises químicas de solos, plantas e fertilizantes.

2. ed. Brasília, DF: Embrapa Informação Tecnológica, 2009 $627 \mathrm{p}$.

SILVA JÚNIOR, M. J.; MEDEIROS, J. F.; OLIVEIRA, F. H. T. DUTRA, I. Acúmulo de matéria seca e absorção de nutrientes pelo meloeiro "Pele de Sapo". Revista Brasileira de Engenharia Agrícola e Ambiental, Campina Grande, v.10, n.2, p. 364-368, dez. 2006TA, C.T.; WEILAND, R.T. Nitrogem partitiong in maize during ear development. Crop Sci., 32:443-451, 1992.

VANCE, C.P.; UHDE-STONE, C.; ALLEN, D.L. phosphorus acquisition. And use: Critical adaptations by plants for securing a nonrenewal bleresource. New phytol., 157: 423-447, 2003.

VIDIGAL S. M.; PACHECO D. D.; FACION C. E. Crescimento e acúmulo de nutrientes pela abóbora híbrida tipo Tetsukabuto. Horticultura Brasileira25: 375 380.2007 .

VIDIGAL, S. M.; PACHECO, D. D.; COSTA, E. L.; FACION, C. E. Crescimento e acúmulo de macro e micronutrientes pela melancia em solo arenoso. Revista Ceres, Viçosa, v. 56, n. 1, p. 112-118, 2009.

VITTI, G. C.; LIMA, E.; CICARONE, F. Nutrição mineral de plantas (ed. FERNANDES, M.S.). SBCS, Viçosa. 432p. 2006.

FARIAS, M. S. S. de. Monitoramento da qualidade da água na Bacia Hidrográfica do rio cabelo. 2006. 152 p. Tese (Doutorado em Engenharia Agrícola) Programa de Pós-Graduação em Engenharia Agrícola, da Universidade Federal de Campina Grande, Campina Grande, 2006.

GRAMOLELLI JÚNIOR, F. Diagnóstico do uso da água na irrigação de culturas na bacia do rio Jundiaí-Mirim / 
SP. 2004. 101 f. Dissertação (mestrado) - Universidade Estadual de Campinas, Faculdade de Engenharia Agrícola, Campinas, SP: [s.n.], 2004.

MANTOVANI, E. C.; BERNARDO, S.; PALARTTI, L. F. Irrigação: princípios e métodos. Viçosa: UFV, 2006. 328 p.

SILVA, I. N.; FONTES, L. de O.; TAVELLA, L . B.; OLIVEIRA, J. B. de.; OLIVEIRA, A. C. de. Qualidade de água na irrigação. Revista Agropecuária Científica no Semiárido - ACSA, v.07, n. 03, p. 01 - 15, jul/set. 2011. Disponível em:<www.cstr.ufcg.edu.br/acsa e http://150.165.111.246/ojspatos/index.php/ACSA/index

>. Acesso em: 15 fev. 2015. 